\title{
Genetic diversity project fights for its life...
}

Vancouver

A combination of political and public controversy has reduced the size and scope of the Human Genome Diversity Project (HGDP), a bold scheme to collect, store and analyse DNA representing the world's ethnic diversity.

This ambitious goal has now become a disparate set of collection projects, funded from a variety of sources. A DNA repository and database - two key components seem unlikely to happen without more funding and broader political support.

Even some of the project's strongest supporters are somewhat pessimistic about its prospects. Hiraku Takebe, professor at the Atomic Energy Research Institute at Kinki University in Osaka, Japan, told the Human Genome Organisation (HUGO) meeting in Vancouver earlier this month that he fears the project is "almost aborted". HUGO began exploring the HGDP formally in 1992, but in recent years hasn't aggressively pursued it, says Takebe.

He adds that, without the inclusion of genomic data from populous countries such as India and China, the Human Genome Project — which is constructing a composite genome by sequencing DNA from several US individuals from a variety of ethnic backgrounds - could more aptly be called the 'Western Nation Genome Project'.

But even without HUGO's backing, the HGDP faces serious obstacles. Some countries, such as New Guinea, are now demanding a fee for each DNA sample that researchers take. Others, such as India, forbid the export of DNA completely.

What's more, says Takebe, other projects with related goals, such as the SNP (singlenucleotide polymorphism) Consortium, could upstage the HGDP's efforts. The consortium, which aims to define the single base-pair gene differences often associated with disease susceptibility or response to drugs, has received US\$50 million from private and public sources.

The HGDP is asking broader questions about other kinds of genetic diversity. But unlike the commercially driven SNP Consortium, the HGDP has always struggled to attract support.

After population geneticist Luigi Luca Cavalli-Sforza of Stanford University conceived the idea, HUGO formed a committee to pursue it, with Cavalli-Sforza as its chair a position he still holds. But the project has met with ambivalence at best from governments and funding agencies. HUGO lacks the resources to support large projects itself.

The United Nations Educational, Scientific and Cultural Organization failed to endorse it in 1995, partly because of the controversy surrounding the project's collecting

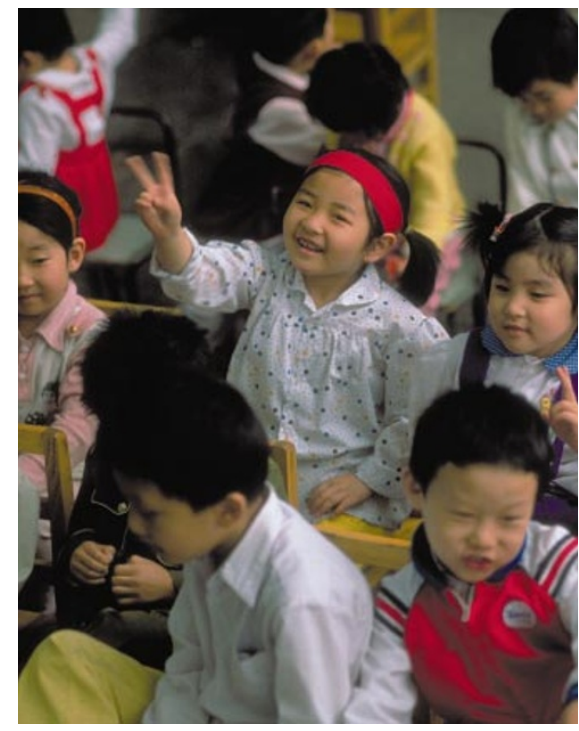

At the margin: ethnic diversity has been omitted from the Human Genome Project.

of genetic samples from populations around the world. And in 1997, a report from the US National Academy of Sciences recommended the US National Science Foundation and National Institutes of Health not to fund the project (see Nature 377, 373; 1995 \& 389, 774; 1997).

"Our lack of funding is a huge issue," says Henry Greely, professor at Stanford Law School and a spokesman for the project. But he denies that it is killing the programme. "Rumours that the HGDP has died, or is in a comatose state, are exaggerated," he says.

One of the most frequent criticisms of human genetics research is that it takes genetic information from populations without giving enough back. Earlier this month, HUGO moved to address this concern with a statement on 'benefits sharing'. But HUGO's new policy is purely advisory, and differs substantially from guidelines drafted by the HGDP (see below).

The current HUGO leadership appears to be ambivalent about the HGDP — at least as an ambitious, centralized effort. HUGO president Lap-Chee Tsui, geneticist-in-chief at the Hospital for Sick Children in Toronto, says the programme doesn't have clearly defined goals and questions.

Tsui says that the HGDP has been framed variously as a search for disease genes, a way to track ethnic migration, and a means to identify disease susceptibility and prevalence in different populations. Greely agrees that the project potentially addresses many research questions. But he disagrees that this is a weakness.

Not everyone is pessimistic about the project's prospects. Walter Bodmer, a geneticist at the University of Oxford and former HUGO president, predicts that, as more scientists become aware of the uses of data on genetic variation, support for the HGDP will grow. "Population variation is only going to become more valuable," says Bodmer. "I think the tide is turning."

Cavalli-Sforza says that the work he and Bodmer have done shows that diversity research is healthy. Scientists in other countries, including India and China, are collecting the same sort of data. "Whether they call themselves HGDP or not really doesn't matter to me," Cavalli-Sforza says. Paul Smaglik

\section{... as companies are urged to share benefits}

\section{Vancouver}

Sharing doesn't always come easily. But it may be necessary to generate research that relies on obtaining genetic samples from people from a variety of geographic locations and ethnic backgrounds.

The Human Genome Organisation (HUGO), at its annual meeting in Vancouver earlier this month, released guidelines encouraging pharmaceutical companies and others to donate 1-3 per cent of their annual net profit to health infrastructure and humanitarian aid. If widely adopted, these guidelines could encourage more countries to participate in efforts such as the Human Genome Diversity Project (see above).

But adoption is unlikely to come easily, admits Bartha Knoppers, chairperson of HUGO's ethics committee, which wrote the guidelines. "At the beginning, it may sound utopian or naive, but if you don't bring it up, the issues don't advance," says Knoppers, a law professor at the University of Montreal.

Many subtleties complicate the matter. For instance, HUGO's guidelines emphasize helping an entire country or community, whereas HGDP's guidelines specifically favour rewarding those who cooperate.
In some cases, this is straightforward. For example, people with Tangiers disease a rare genetic condition resulting in lower levels of HDLC, or 'good' cholesterol - could be easily rewarded for their involvement if a drug is developed, says Kare Berg, a geneticist at the University of Oslo.

But tracking down everyone who has ever participated in a cancer trial that may have contributed to a successful therapy years after their participation is more complicated, says Dorothy Wertz, a sociologist at the Eunice Kennedy Shriver Center in Waltham, Massachusetts. 